\title{
Efeito de preparados caseiros no controle da queima-acinzentada, na cultura da cebola.
}

\author{
Pedro Boff; Paulo A. de S. Gonçalves; João F. Debarba. \\ EPAGRI - Estação Experimental de Ituporanga, C. postal 121, 88400-000 Ituporanga, SC.
}

\section{RESUMO}

Agricultores do Alto Vale do Itajaí (SC), vem utilizando preparados caseiros no tratamento fitossanitário da cebola, cuja principal doença, durante a fase de muda, é a queima-acinzentada, causada pelo fungo Botrytis squamosa. Neste trabalho, realizado nos anos de 1993, 94 e 95, no período de muda da cebola, durante a fase de canteiro, avaliou-se o efeito de extratos alcóolicos de Matricaria chamomilla, Mentha glacilis, alho e própolis; cinza vegetal e cal; soluções de $\mathrm{B}+\mathrm{Zn}, \mathrm{KMnO}_{4}, \mathrm{NaClO}$, Sílica-gasil, creolina, formalina; calda sulfocálcica, calda bordalesa, cânfora, enxofre, enxofre+silicato+propólis e o fungo antagonista, Gliocladium roseum, sobre o desenvolvimento da queima-acinzentada. A aplicação dos produtos foi semanal e as concentrações foram ajustadas em ensaio preliminar. $\mathrm{O}$ estudo de eficiência mostrou que Gliocladium roseum (108 esporos/ml) igualou-se ao fungicida vinclozolin $(0,075 \%)$, no controle da queima-acinzentada em 1994/ 95. No ciclo de 1995/96, maior sobrevivência de plantas e/ou maior número de plantas aptas ao transplante foram obtidos nos tratamentos com cinza vegetal, calda bordalesa $(0,5 \%)$ e a mistura de enxofre + silicato + extrato de própolis, comparados com o tratamento padrão, com fungicida. As soluções de $\mathrm{KMnO}_{4}, \mathrm{NaClO}$, cânfora, enxofre e sílica-gasil não mostraram diferença com a testemunha não tratada. A adubação orgânica de base, em 1995, proporcionou mudas com menor intensidade de $B$. squamosa e maior índice de sobrevivência das mesmas do que adubação mineral, independentemente da formulação.

Palavras-chave: Allium cepa, controle biológico, Botrytis squamosa, Gliocladium roseum.

\begin{abstract}
Alternative formulations for control of Botrytis squamosa on onion.

Santa Catarina State farmers in the "Alto Vale do Itajaî" region are using several home-made products to control onion pests, where leaf blight of onion (Botrytis squamosa) is the main nursery disease. This research was carried out during the nursery period in 1993, 94 and 95 , in order to evaluate traditional formulations against leaf blight of onion. The formulations studied were alcoholic extracts of Matricaria chamomilla, Mentha glacilis, garlic and propolis; wood ash, lime, solution of $\mathrm{B}+\mathrm{Zn}, \mathrm{KMnO}_{4}, \mathrm{NaClO}$, "silica-gasil", creoline, formalin, Bordeaux mixture, sulphur, camphor, and the antagonist Gliocladium roseum. The formulations were used weekly in concentrations previously tested to avoid phytotoxicity. In the onion cycle 1994/95, G. roseum (108 spores/ml) reduced leaf blight of onion with the effect comparable to the standard fungicide vinclozolin $(0.075 \%)$. In $1995 / 96$, the survival of onion and the number of plants suitable for transplanting were highest using wood ash, Bordeaux mixture $(0.5 \%)$ and a mixture of sulphur $+\mathrm{Na}_{2} \mathrm{SiO}_{4}+$ propolis extract, when compared to the fungicide used as a standard treatment. No leaf blight control effect was observed with sprays of $\mathrm{KMnO}_{4}, \mathrm{NaClO}$, "camphor", sulphur and "sílica-gasil". Organic fertilizer increased the survival of onion seedlings and reduced Botrytis squamosa, irrespective of formulation, during the $1995 / 97$ period.
\end{abstract}

Keywords: Allium cepa, biological control, Botrytis squamosa, Gliocladium roseum.

\section{(Aceito para publicação em 29 de março de 1999).}

A agricultura familiar praticada antes do período da revolução verde guardava técnicas peculiares, onde a propriedade agrícola tinha seus próprios recursos para superar as adversidades do ambiente e os desequilíbrios biológicos, tais como os surtos de pragas e as epidemias de doenças. As sementes mantidas nas propriedades continham características de rusticidade e adaptabilidade às condições edafo-climáticas locais, além de oferecer produtividade estável ao longo do tempo (Altieri, 1989). O isolamento geográfico natural de áreas agrícolas, na microrregião de Tabuleiros (SC), permitiu conservar a diversidade genética da cebola local, conhecida como "Crioula". Isto possibilitou com que fosse utilizada, até hoje, como base genética, nos trabalhos de melhoramento vegetal, bem como na produção de bulbos, representando $80 \%$ do cultivo comercial do estado de Santa Catarina. Pela sua rusticidade, as populações de "Crioula" vêm sendo cultivadas em Santa Catarina, com pouco uso de agroquímicos e em muitas propriedades, aplicando-se, apenas certos pre- parados caseiros, como a cal, cinza vegetal, extratos de plantas, creolina, etc.

O surgimento dos pesticidas industriais, na década de 40, direcionou o sistema de cultivo, para a demanda exclusiva de agroquímicos. Como consequiência, vem ocorrendo uma grande pressão de seleção de patógenos e pragas, os quais tornam-se resistentes à ação de pesticidas (Ghini, 1987), além destes produtos químicos contribuírem para a contaminação ambiental com graves riscos à saúde humana (Bull \& Hathaway, 1986). Segundo Chaboussou (1987), há 
também efeitos iatrogênicos sobre a planta, cuja aplicação de pesticidas sintéticos induz o estado de proteólise dominante, em que os aminoácidos livres na seiva favorecem o ataque de fungos e de insetos sugadores e/ou raspadores. Em termos de mercado, alimentos produzidos organicamente encontram-se em crescente demanda (Kroth et al., 1996), os quais requerem alternativas não tóxicas para o manejo fitossanitário, quando este for necessário.

Seja para redução de pesticidas, nos sistemas convencionais de cultivo ou para atender aos sistemas de produção alternativos aos agroquímicos, há necessidade de se avaliar práticas simples, para serem estudadas no enfoque da sustentabilidade dos agroecossistemas e adaptadas à realidade sócio-econômica, tanto pela sua inocuidade ao homem e ao meio ambiente, quanto pelo acesso e facilidade de adoção (Santos et al., 1988).

Métodos de controle de pragas e doenças, alternativos aos agroquímicos, têm sido documentados por vários autores (Guerra, 1985; Garofalo, 1988, Santos et al., 1988). Muitos extratos vegetais são considerados eficientes no controle de doenças, entre os quais a camomila (Matricaria chamomilla L.), a menta (Mentha spp) e o alho (Allium sativum L.) (Guerra, 1985). Extrato de própolis, também, tem mostrado eficiência superior a certos fungicidas, no controle de doenças de frutas e hortaliças (Garofalo, 1988). Na extração de substâncias de origem vegetal, a metodologia mais simples é a infusão; porém, o uso de água quente pode inativar os componentes, com propriedades fitoterápicas. A maceração hidroalcoólica é uma opção mais eficiente na obtenção de extratos vegetais com finalidade fitoterápica (Guerra, 1985). Outros produtos à base de enxofre e cobre são conhecidos há vários anos na proteção de plantas. O enxofre é indicado para o controle de oídio, além de vários insetos-praga. A calda sulfocálcica, cujo principal constituinte é o polissulfeto de cálcio, é indicada contra cochonilhas, ácaros e fungos (Guerra, 1985). Quando a temperatura for abaixo de $20^{\circ} \mathrm{C}$, o enxofre perde sua eficiência, sendo indicado o permanganato de potássio (125 g/100 1) (Guerra, 1985). A calda bordalesa teve descoberta sua propriedade fitoterápica no fim do século passado e o seu uso sobreviveu à revolução verde, sendo eficiente no controle de várias doenças. Vários outros produtos, incluindo cal, cinza, creolina e sal amargo, são citados por agricultores, como eficientes no tratamento fitossanitário da cebola. Na cultura da cebola no sul do Brasil as doenças mais importantes da parte aérea da cebola são o míldio, a mancha-púrpura e a queimaacinzentada, sendo esta última de ocorrência mais frequiente na fase de muda (Boff, 1994).

Este trabalho teve o objetivo de avaliar a eficiência de preparados caseiros no controle da queima-acinzentada da cebola, causada pelo fungo Botrytis squamosa.

\section{MATERIAL E MÉTODOS}

O trabalho foi conduzido na Estação Experimental da EPAGRI, em Ituporanga, situada a $475 \mathrm{~m}$ do nível do mar, na região do Alto Vale do Itajaí (SC). Foram realizados três experimentos, durante o período de muda da cebola, nos ciclos de cultivo 1993/94, 1994/95 e 1995/96, correspondendo, aos experimentos 1,2 , e 3 , respectivamente. Utilizou-se a população "crioula", semeada em canteiros com densidade de $3 \mathrm{~g}$ de sementes/m2, a uma profundidade de $2 \mathrm{~cm}$, tendo como cobertura póde-serra de Pinus, resultando numa densidade média inicial de 450 plântulas por $\mathrm{m} 2$. O preparo do solo foi feito pelo sistema convencional com adubação de $300 \mathrm{~g} / \mathrm{m} 2$ de NPK, da fórmula de 5-20$10\left(\mathrm{~N}, \mathrm{P}_{2} \mathrm{O}_{5}, \mathrm{~K}_{2} \mathrm{O}\right)$. No experimento três, $1995 / 96$, as parcelas com adubação orgânica, receberam 5 litros de composto termófilo por m2. Não houve necessidade de controlar os insetos-praga e as plantas daninhas foram arrancadas manualmente. A irrigação, quando necessária, foi feita em dias anteriores à aplicação dos preparados caseiros. As aplicações dos produtos foram realizadas, semanalmente, no período da manhã, a partir do estádio de duas folhas verdadeiras expandidas, até 20 dias antes do arranquio das mudas. Como adesivo foi utilizado pectina de laranja $(0,1 \%)$, obtida pela liquefação de 300 gramas da entrecasca do fruto de laranja, em 1 litro de água, fervendo-se até reduzir o volume para $50 \%$ e, após, coando-se. As aplicações líquidas foram feitas com pulverizador manual, marca Brüedgem, ajustando-se o volume conforme o estádio da cultura. As concentrações dos produtos, nas formulações caseiras foram ajustadas em ensaios preliminares, de modo a não causarem fitotoxidez à planta, em nenhum dos seus estádios de desenvolvimento.

No experimento 1 (1993/94) avaliaram-se os seguintes tratamentos: 1) Vinclozolin, 75 g p. a. $/ 1001$ (tratamento padrão); 2) Cinza vegetal, $50 \mathrm{~g} / \mathrm{m} 2$ oriunda da queima de lenha de bracatinga, aplicação em pó; 3) Extrato de camomila, obtido por maceração alcoólico $\left(70^{\circ} \mathrm{GL}\right)$, de $100 \mathrm{~g}$ de flor seca / 1 , sendo aplicado na concentração de 5\% do extrato; 4) Calda bordalesa, na proporção de 0,5:1,0:100 de sulfato de cobre $(\mathrm{kg})$, cal apagada $(\mathrm{kg})$ e água (1), respectivamente; 5) Testemunha (sem aplicação); 6) Calda sulfocálcica, $0,15^{\circ}$ Be (graus Boumé); 7) Silica-gasil-114, a $0,1 \%$; 8) Permanganato de potássio $\left(\mathrm{KMnO}_{4}\right)$, em solução de $0,3 \%$; 9) Extrato hidro-alcoólico de própolis, obtido por maceração de $200 \mathrm{~g}$ de própolis bruto, moído, por litro de álcool $\left(70^{\circ}\right.$ GL), durante 20 dias, sendo, após, o mesmo própolis macerado em $11 \mathrm{de}$ água e misturado na proporção de 1:2, respectivamente, os extratos alcoólico e o acuoso, e aplicado na concentração de $0,2 \%$ do extrato; 10) Enxofre pó molhável, 0,2\%; 11) Cal apagada, aplicando-se $40 \mathrm{~g} / \mathrm{m} 2$, em pó; 12) Chorume, obtido da mistura de 91 de esterco bovino + 11 de esterco de aves, em 91 de água, deixando-se fermentar por 10 dias e após, diluindo-se a $5 \%$. O delineamento experimental foi blocos ao acaso com quatro repetições e a unidade experimental de $3 \mathrm{~m} 2$, com área útil de $1 \mathrm{~m} 2$.

No experimento 2 conduzido no ciclo de cultivo 1994/95, os tratamentos foram: 1) Vinclozolin, $75 \mathrm{~g} \mathrm{p}$. a. /100 1 d'água; 2) Cinza vegetal, $50 \mathrm{~g} / \mathrm{m} 2$, aplicação em pó; 3) Extrato de camomila, obtido por maceração alcoólica $\left(70^{\circ} \mathrm{GL}\right)$ de $100 \mathrm{~g}$ de flor seca $/ 1$, sendo aplicado na concentração de $5 \%$ do extrato; 4) Calda bordalesa, na proporção de 0,5:1,0:100 de sulfato de cobre (kg), cal 
apagada (kg) e água (1), respectivamente; 5) Extrato de própolis, $(0,2 \%)$ misturado com enxofre pó molhável $(0,25 \%)+$ silicato de sódio comercial $(0,5 \%) ; 6)$ Testemunha (sem aplicação); 7) Extrato de alho, obtido por maceração alcoólica $\left(70^{\circ} \mathrm{GL}\right)$ de $100 \mathrm{~g}$ de bulbilho por 1, aplicando-se na concentração de 2\% do extrato; 8) Calda sulfocálcica $\left(0,15^{\circ} \mathrm{Be}\right)$; 9) Extrato de menta, obtido por maceração de $200 \mathrm{~g}$ de folha seca $/ 1$ de álcool $\left(70^{\circ} \mathrm{GL}\right)$, sendo aplicado na concentração de $5 \%$ do extrato; 10 ) Adubo foliar composto por tetraborato de sódio + sulfato de zinco na proporção de $3 \mathrm{~g} / \mathrm{l}$ de $\mathrm{Na}_{2} \mathrm{~B}_{4} \mathrm{O}_{7}$ e $5 \mathrm{~g} / \mathrm{l}$ de $\mathrm{ZnSO}_{4}$; 11) Silica-gasil-114, $0,1 \% ; 12)$ Permanganato de potássio $\left(\mathrm{KMnO}_{4}\right)$, em solução de $0,3 \%$; 13) Extrato hidro-alcoólico de própolis, obtido por maceração de 200 gramas/l de própolis bruto, moído, em álcool (70 $\left.{ }^{\circ} \mathrm{GL}\right)$, durante 20 dias, sendo, após, o mesmo própolis, macerado em 11 de água e misturado na proporção de $1: 2$, respectivamente, os extratos alcoólicos e acuoso, sendo aplicado a 0,2\% do extrato; 14) Enxofre pó molhável, 0,2\%; 15) Creolina comercial, $0,25 \%$; 16) Gliocladium roseum, na concentração de 104 esporos/ml; 17) G. roseum, na concentração 106 esporos/ml; 18) $G$. roseum, na concentração de 108 esporos/ml. O isolado do fungo antago- nista, Gliocladium roseum, foi cedido pelo prof. John C. Sutton - Universidade de Guelph, Canada e multiplicado em grãos de trigo autoclavados, a $20^{\circ} \mathrm{C}$, no escuro. $\mathrm{O}$ delineamento experimental foi de blocos ao acaso com 4 repetições e parcelas de tamanho igual ao primeiro experimento.

No experimento 3, conduzido no ciclo de cultivo 1995/96, o delineamento experimental foi blocos ao acaso em arranjo fatorial, tendo como primeiro fator preparado caseiro, em 18 níveis, correspondentes aos tratamentos do experimento realizado em 1994/95, acima descrito, e o fator adubação de base em dois níveis: orgânica e mineral. Como orgânica, utilizou-se $5 \mathrm{l} / \mathrm{m} 2$ do produto, oriundo da compostagem termófila de capim Cameroon (Pennisetum purpureum) triturado, descarte de cebola triturada e esterco bovino, na proporção de $1: 1: 1$, respectivamente. Como adubação mineral utilizou-se $300 \mathrm{~g} / \mathrm{m} 2$ de NPK, na fórmula 5-20-10 (N, $\left.\mathrm{P}_{2} \mathrm{O}_{5}, \mathrm{~K}_{2} \mathrm{O}\right)$.

As avaliações foram realizadas, considerando-se: a) fitotoxidez aparente, avaliando-se as alterações na arquitetura da planta e queima de tecidos nas 48 $\mathrm{h}$ subseqüientes à aplicação do produto; b) número de plantas sobreviventes, por ocasião do transplante; c) número de plantas aptas ao transplante, com diâ- metro de pseudocaule acima de $4 \mathrm{~mm}$; d) peso médio por planta; e) severidade de Botrytis squamosa, considerando-se a área abaixo da curva de progresso da doença. A intensidade de $B$. squamosa foi avaliada pela proporção de área foliar necrosada, identificada pela presença do sintoma típico de queima descendente de folhas de aspecto acinzentado. $\mathrm{Na}$ parcela útil, 16 quadrados de $25 \times 25 \mathrm{~cm}$ foram avaliados comparando-se a área foliar necrosada por queimaacinzentada em relação ao total, com auxilio de escala diagramática de severidade $(0-100 \%)$. Periodicamente, amostras de folhas foram submetidas à câmara umida para estimular a esporulação do fungo, com posterior identificação, conferindo a representatividade do sintoma considerado como ataque de $B$. squamosa. No ciclo de 1993/94, foi considerada a porcentagem de área foliar lesionada por B. squamosa, nas últimas três semanas de pulverizações, não tendo sido realizadas avaliações anteriores pela baixa incidência da doença.

\section{RESULTADOS E DISCUSSÃO}

No primeiro ensaio 1993/94, houve diferença significativa entre os tratamentos, para severidade da doença e número de plantas sobreviventes (Tabela 1). Plan-

Tabela 1. Efeito de preparados caseiros na percentagem de área foliar necrosada por ataque de Botrytis squamosa (severidade); número de plantas sobreviventes, por grama de semente plantada (sobrevivência) e número de plantas aptas ao transplante, com diâmetro do pseudocaule maior que 4 mm (P. aptas). Ituporanga (SC), EPAGRI - Est. Exp. de Ituporanga. 1993/94.

\begin{tabular}{lccc}
\hline \multicolumn{1}{c}{ Tratamento } & Severidade ${ }^{1}(\%)$ & Sobrevivência & P. aptas ns \\
\hline 1 - Vinclozolin (0,075 \%) & $20,2 \mathrm{a}$ & $165,8 \mathrm{a}$ & 80,8 \\
2 - Cinza vegetal (50g/m2) & $21,6 \mathrm{a}$ & $130,7 \mathrm{~b}$ & 60,4 \\
3 - Extrato de camomila (0,5\%) & $19,6 \mathrm{~b}$ & $118,1 \mathrm{~b}$ & 55,5 \\
4 - C. bordalesa (0,5\% de CuSO4) & $17,7 \mathrm{c}$ & $127,9 \mathrm{~b}$ & 58,5 \\
5 - Testemunha & $21,2 \mathrm{a}$ & $135,7 \mathrm{~b}$ & 50,5 \\
6 - Calda sulfocálcica (0,150 Be) & $20,6 \mathrm{a}$ & $119,8 \mathrm{~b}$ & 49,5 \\
7 - Silica-gasil - 114 (0,1\%) & $21,0 \mathrm{a}$ & $128,9 \mathrm{~b}$ & 49,4 \\
8 - KMnO4 (0,3\%) & $21,2 \mathrm{a}$ & $136,9 \mathrm{~b}$ & 63,5 \\
9 - Extrato de própolis (0,2\%) & $21,3 \mathrm{a}$ & $127,9 \mathrm{~b}$ & 60,2 \\
10 - Enxofre PM (0,2\%) & $21,1 \mathrm{a}$ & $130,3 \mathrm{~b}$ & 50,2 \\
11 - Cal apagada (40 g/m2) & $18,4 \mathrm{c}$ & $155,9 \mathrm{a}$ & 74,6 \\
12 - Chorume (5\%) & $21,7 \mathrm{a}$ & $120,6 \mathrm{~b}$ & 57,9 \\
\hline C.V. (\%) & 26,6 & 15,4 & 3,5 \\
\hline
\end{tabular}

*/ Valores seguidos pela mesma letra, na vertical, não diferem entre si pelo teste de agrupamento Scott Knot, ao nível de 5\% de probabilidade.

1/ Média das últimas três avaliações 
Tabela 2. Efeito de preparados caseiros na área abaixo da curva da proporção de área foliar necrosada da queima-acinzentada (Botrytis squamosa-ACPD); número de plantas sobreviventes (sobrevivência) e número de plantas aptas ao transplante, com diâmetro do pseudocaule maior que 4 mm (P. aptas) por grama de semente plantada. Ituporanga (SC), EPAGRI - Estação Experimental de Ituporanga. $1994 / 1995$.

\begin{tabular}{|c|c|c|c|c|c|c|}
\hline \multirow{2}{*}{ CARACTERES ${ }^{\mathrm{X} /}$} & \multicolumn{6}{|c|}{ EFEITOS (SIJ) } \\
\hline & $1 \times 2$ & $1 \times 3$ & $1 \times 4$ & $2 \times 3$ & $2 \times 4$ & $3 \times 4$ \\
\hline NTV & $1,527^{\star \star}$ & $-20,240 \star \star$ & 34,127 ** & $-14,207^{\star \star}$ & $-32,440 * \star$ & 74,793 ** \\
\hline PTV & $51,920 * *$ & $-96,513^{\star \star}$ & $77,553^{\star \star}$ & $-65,313^{\star *}$ & $-224,447 * \star$ & $530,120 * *$ \\
\hline CVA & $0,627 * *$ & $0,227 * *$ & $-0,363^{\star \star}$ & $-0,229 * *$ & $0,461 * *$ & 1,281 ** \\
\hline DVA & $0,010 * *$ & $0,011 * *$ & $0,013 * *$ & $0,002 * *$ & $0,035 * *$ & $-0,055^{\star *}$ \\
\hline NIF & $-0,213^{* *}$ & $1,286 * *$ & $0,686^{* \star}$ & $0,953 * *$ & $3,953^{* \star}$ & $-1,146 * *$ \\
\hline NFF & $-0,227 * *$ & $1,307 * *$ & $0,573 * *$ & $1,107 * *$ & $3,173 * *$ & $-1,293 * *$ \\
\hline FIB & $-0,167^{\star *}$ & $0,203 * *$ & $0,070 * *$ & $-0,150 * *$ & $0,117 * *$ & $-0,053^{* *}$ \\
\hline $\mathrm{ALT}$ & $1,765^{\star *}$ & $-0,652^{\star *}$ & $-0,969 * *$ & $-0,195 * *$ & $-1,652^{* *}$ & 2,351 ** \\
\hline
\end{tabular}

*/ Valores seguidos pela mesma letra, na vertical, não diferem entre si pelo teste de agrupamento Scott-Knot, ao nível de 5\% de probabilidade.

tas tratadas com extrato de camomila $(0,5 \%)$, calda bordalesa $(0,5 \%$ de $\left.\mathrm{CuSO}_{4}\right)$ e cal apagada (40 g/m2) apresentaram menor proporção de queimaacinzentada do que o padrão vinclozolin, que foi igual à testemunha. Maior sobrevivência de plantas foi observada com tratamento por vinclozolin e cal apagada, embora, não diferisse dos demais tratamentos, quanto ao número de plantas aptas ao transplante e ao peso médio por planta.

As avaliações realizadas no ciclo de cultivo 1994/95 (Tabela 2) demonstraram haver controle de $B$. squamosa, através do antagonista Gliocadium roseum (108 esp/ml), equiparado ao padrão (vinclozolin), considerando-se a severidade da doença (ACPD) e o número de plantas sobreviventes. Plantas tratadas com cinza vegetal e G. roseum (106 e 108 esporos por $\mathrm{ml}$ ) proporcionaram sobrevivência igual ao padrão (vinclozolin), embora, na avaliação do número de plantas aptas ao transplante e peso médio por planta, os tratamentos não diferiram entre si.

No experimento 3, realizado no ciclo de cultivo 1995/96 (Tabela 3), os fatores adubação e preparados caseiros, variaram, independentemente, ou seja a interação não foi significativa, para todas as variáveis consideradas: intensidade da queima-acinzentada, sobrevivência de plantas, número de plantas aptas ao transplante (diâmetro do pseudocaule maior que $4 \mathrm{~mm}$ ) e peso médio por planta. A adubação orgânica proporcionou maior sobrevivência de mudas, maior número de plantas aptas ao transplante e menor intensidade de B. squamosa, do que a adubação mineral, em todas os preparados testadas. No estudo da eficiência dos preparados caseiros, melhores resultados, na avaliação do número de plantas aptas ao transplante, foram obtidos com a mistura de extrato de própolis+enxofre+silicato de sódio, calda bordalesa e cinza vegetal, comparados à testemunha, sendo que o padrão apresentou melhor índice entre todos os tratamentos (Tabela 3). O peso médio por planta não diferiu, entre os preparados testados.

Considerando os resultados obtidos nos três anos, observa-se que o uso da calda bordalesa $\left(0,5 \%\right.$ de $\left.\mathrm{CuSO}_{4}\right)$, cinza vegetal $(50 \mathrm{~g} / \mathrm{m} 2)$, extrato de própolis $(0,2 \%)$ e $G$. roseum (108 esp/ml) reduziu a intensidade da queima-acinzentada equiparados ao padrão em pelo menos um dos ciclos da cultura (Tabelas 1, 2 e 3). James \& Sutton (1996) obtiveram redução de $50 \%$ da incidência de $B$. squamosa, em cebola, com aplicação de G. roseum, a $5 \times 106$ esporos $/ \mathrm{ml}$, em comparação ao uso de clorotalonil; no entanto, foi suficiente para evitar perdas econômicas. No presente trabalho, pelo menos em um dos ensaios, a aplicação de G. roseum (108 esp/ml) reduziu a severidade de $B$. squamosa e aumentou a respectiva sobrevivência de plantas, igualando-se ao padrão vinclozolim. O uso do antagonista $G$. roseum, no controle de Botrytis spp. tem sido promissor também em outras culturas como o moranguinho
(Valdebenito-Sanhueza, 1997). Os extratos vegetais de camomila, alho e menta, o permanganato de potássio, o adubo foliar (boro+zinco), a creolina, o enxofre e a sílica não destacaram-se dos demais tratamentos, em nenhum dos experimentos, exceto o extrato de camomila no período de 1993/94, que apresentou melhor controle da queimaacinzentada do que o padrão. $\mathrm{O}$ efeito de extratos de alho sobre fungos foi estudado também por Barros et al. (1995), que observaram inibição de crescimento micelial de Curvularia spp e Alternaria spp. Neste trabalho, o extrato de alho não destacou-se dos demais tratamentos, quanto ao controle de $B$. squamosa. A variabilidade na composição química dos preparados estudadas e os diferentes mecanismos envolvidos na ação contra B. squamosa, requer a realização de outros experimentos com o objetivo de estabelecer dosagens e freqüência de aplicação adequadas ou a combinação das mesmas. $\mathrm{O}$ uso de composto termófilo mostrou-se altamente promissor no controle da queima-acinzentada, mesmo que esta seja uma doença da parte aérea. Zhang et al.(1998) observaram que a adição de composto em pepino e Arabidopsis sp. induziu resistência sistêmica adquirida contra antracnose e Pseudomonas syringae, respectivamente. A autoclavagem de similar composto destruiu o efeito da resistência induzida, mostrando ser a indução de natureza biológica.

Conclui-se que certos preparados caseiros têm eficiência semelhante à do 
Tabela 3. Efeito de preparados caseiros na área abaixo da curva da proporção de área foliar necrosada da queima-acinzentada (Botrytis squamosa-ACPD); número de plantas sobreviventes (sobrevivência) e número de plantas aptas ao transplante, com diâmetro do pseudocaule maior que 4 mm (P. aptas), por grama de semente plantada. Ituporanga (SC), EPAGRI - Estação Experimental de Ituporanga. 1995/1996.

\begin{tabular}{|c|c|c|c|}
\hline Tratamento & $\begin{array}{c}\text { B. squamosa - } \\
\text { ACPD }\end{array}$ & Sobrevivência & P. aptas ns \\
\hline 1 - Vinclozolin $(0,075 \%)$ & $111,8 \quad b$ & $216,0 \mathrm{a}$ & $108,4 \mathrm{a}$ \\
\hline 2 - Cinza vegetal $\left(50 \mathrm{~g} / \mathrm{m}^{2}\right)$ & $142,6 \mathrm{a}$ & $151,0 \quad b$ & $75,4 \mathrm{~b}$ \\
\hline 3 - Extrato de camomila $(0,5 \%)$ & $160,1 \mathrm{a}$ & $138,5 b$ & $67,3 \mathrm{c}$ \\
\hline 4 - C. bordalesa $\left(0,5 \%\right.$ de $\left.\mathrm{CuSO}_{4}\right)$ & $147,0 \mathrm{a}$ & $152,9 \quad b$ & $79,3 \mathrm{~b}$ \\
\hline 5 - Ext. própolis+enxofre+silicato & $161,2 \mathrm{a}$ & $195,5 \mathrm{a}$ & $73,0 \mathrm{~b}$ \\
\hline 6 - Testemunha & $154,8 \mathrm{a}$ & $112,2 b$ & $46,4 \mathrm{c}$ \\
\hline 7 - Extrato de alho $(0,2 \%)$ & $169,7 \mathrm{a}$ & $127,8 \quad b$ & $54,6 \mathrm{c}$ \\
\hline 8 - Calda sulfocálcica $(0,15$ 으 Be) & $167,1 \mathrm{a}$ & $129,3 \quad b$ & $58,8 \mathrm{c}$ \\
\hline 9 - Extrato de menta (1\%) & 163,6 a & $126,3 \quad b$ & $54,9 \mathrm{c}$ \\
\hline 10- Micronutrientes $(B+Z n)$ & $184,6 \mathrm{a}$ & $89,5 \quad b$ & $40,5 \mathrm{c}$ \\
\hline 11- Silica-gasil-114 (0,1\%) & $163,2 \mathrm{a}$ & $133,4 \quad b$ & $56,9 \mathrm{c}$ \\
\hline 12- $\mathrm{KMnO} 4(0,3 \%)$ & $151,0 \mathrm{a}$ & $149,2 \quad b$ & $60,7 \mathrm{c}$ \\
\hline 13- Extrato de própolis $(0,2 \%)$ & $158,3 \mathrm{a}$ & $122,0 \quad b$ & $63,0 \mathrm{c}$ \\
\hline 14- Enxofre PM $(0,2 \%)$ & $176,7 \mathrm{a}$ & $127,3 \mathrm{~b}$ & $62,0 \mathrm{c}$ \\
\hline 15- Creolina $(0,25 \%)$ & $166,2 \mathrm{a}$ & $129,0 \quad b$ & $57,5 \mathrm{c}$ \\
\hline 16- Gliocladium roseum ( $\left.10^{4} \mathrm{esp} / \mathrm{ml}\right)$ & $154,0 \mathrm{a}$ & $141,8 \quad b$ & $63,6 \mathrm{c}$ \\
\hline 17- G. roseum (106 esp/ml) & $168,0 \mathrm{a}$ & $139,0 \quad b$ & $63,0 \mathrm{c}$ \\
\hline 18- G. roseum $\left(10^{8} \mathrm{esp} / \mathrm{ml}\right)$ & $160,1 \mathrm{a}$ & $143,4 \quad b$ & $59,6 \mathrm{c}$ \\
\hline C.V. (\%) & 9,9 & 24,7 & 25,4 \\
\hline Adubação & $\mathrm{F}^{* *}$ & $\mathrm{~F}^{* \star}$ & $\mathrm{F}^{\star \star}$ \\
\hline 1 - Orgânica & 151,1 & 155,5 & 70,2 \\
\hline 2 - Mineral & 167,0 & 124,0 & 57,1 \\
\hline
\end{tabular}

*/ Valores seguidos pela mesma letra, na vertical, não diferem entre si pelo teste de agrupamento Scott-Knot, ao nível de $5 \%$ de probabilidade.

fungicida padrão para o controle da queima-acinzentada na cultura da cebola. Do mesmo modo o uso da adubação orgânica fortalece a muda e reduz a intensidade da doença.

\section{LITERATURA CITADA}

ALTIERI, M.A. Agroecologia: as bases cientifícas da agricultura alternativa. Rio de Janeiro, PTA/FASE, 1989. 240 p.

BARROS, S.T.; OLIVEIRA, N.T. de; MAIA, L.C. Efeito de extratos de alho (Allium sativum) sobre o crescimento micelial e germinação de conídios de Curvularia spp. e Alternaria spp. Summa Phytopathologica, São Paulo, v. 12, p. 168-170, 1995.

BOFF, P. O complexo Botrytis spp, causando doenças em cebola. Agropecuária catarinense, Florianópolis, v. 7, n. 3, p. 14-16, 1994.

BULL, D.; HATHAWAY, D. Pragas e venenos; agrotóxicos no Brasil e no terceiro mundo. Rio de janeiro, Ed.Vozes, 1986, 235 p.
CHABOUSSOU, F. Plantas doentes pelo uso de agrotóxicos: a teoria da trofobiose. Trad. M.J. Grazzelli. Porto Alegre, L e PM, 1987. 256 p. GAROFALO, F. Il propoli nella difesa delle piante. Torino, Ass. Suolo e salute, 1988. 38 p.

GHINI, R. Ocorrência e adaptabilidade de linhagens de Botrytis squamosa resistentes a fungicidas do grupo dos benzimidazóis e ditiocarbamatos. Piracicaba, ESALQ, 1987, 1143 p. (Tese DS)

GUERRA, M. de S. Receituário caseiro: Alternativas para controle de pragas e doenças de plantas cultivadas e de seus produtos. Brasília, EMBRATER, 1985. 166 p.

JAMES, T.D.W.; SUTTON, J.C. Biological control of botrytis leaf blight of onion by Gliocladium roseum applied as sprays with and fabric applicators. European Journal of Plant Pathology, v. 102, n. 3, p. 265-275, 1996

KROTH, L.T.; BET, M.; KLEVESTON, R.; KREUTZ, C.L. Receptividade do consumidor de Florianópolis a hortigranjeiros sem agrotóxicos. Agropecuária catarinense, Florianópolis, v. 9, n. 4, p. 7-10, 1996.
SANTOS, J.H.R dos; GADÊLHA, J.E.R.; CARVALHO, M.L.; PIMENTEL, J.V.F.; JULZO, P.V.M.R. Controle alternativo de pragas e doenças. Fortaleza, Ed. UFC, 1988. 216 p.

VALDEBENITO-SANHUEZA, R.M.; SUTTON, J.C.; PERAZZOLO, I.; CZERMAINSKI, A.B.C. Controle biológico de Botrytis cinerea em morangueiros cultivados em estufa. Fitopatologia Brasileira, Brasília, v. 22, n. 1, p. 69-73, 1997.

ZHANG, W.; HAN, D.Y.; DICK, W.A.; DAVIS, K.R.; HOITINK, H.A.J. Compost and compost water extract-induced systemic acquired resistance in cucumber and Arabidopsis. Phytopathology, v. 88, n. 5, p. 450-455, 1998. 